\title{
Quebec sticks with CR mammography machines
}

$\mathrm{O}$ ntario is replacing computed radiography $(\mathrm{CR})$ mammography machines after a major study found them to be less effective than an alternative technology but Quebec is not about to do the same. While some doctors claim Quebec is prioritizing cost over patient safety, other health officials and radiologists argue the Ontario study doesn't apply across Canada.

Dr. André Constantin, president of the Association des Radiologistes du Québec (ARQ), notes detection rates remained stable after the introduction of $\mathrm{CR}$ machines, and that the predominant brand of CR machine examined in the Ontario study (Kodak-Carestream) represents only 6\% of machines in Quebec.

But according to Dr. John Keyserlingk, founder of the Ville Marie Medical Center in Montréal, Quebec "a CR is a CR is a CR." He believes cost is the real reason Quebec isn't following Ontario's lead. Digital direct radiography (DR) machines cost around $\$ 500000$ to $\$ 600000$, or at least five times as much as CR machines.

Seventy-five percent of mammography machines in Quebec (108 total) use CR technology, compared to $25 \%$ in Ontario. Health officials in New Brunswick and Alberta, which have only a few CR machines, are considering phasing them out. Victoria, British Columbia, has one CR machine, which will stay, at least for now, according to $\mathrm{BC}$ officials.

Dr. Sarkis Meterissian, director of the Cedars Breast Clinic at the McGill University Health Centre in Montréal was also disappointed by the ARQ's stance. "There's absolutely no doubt in my mind and in a lot of experts' minds that digital is better."

As to why cost would be a barrier to a mammography shift in Quebec, Mike McBane, national coordinator of the Canadian Health Coalition, points to the fact that the province has taken a more privatized approach to radiology, meaning physicians often pay for the machines

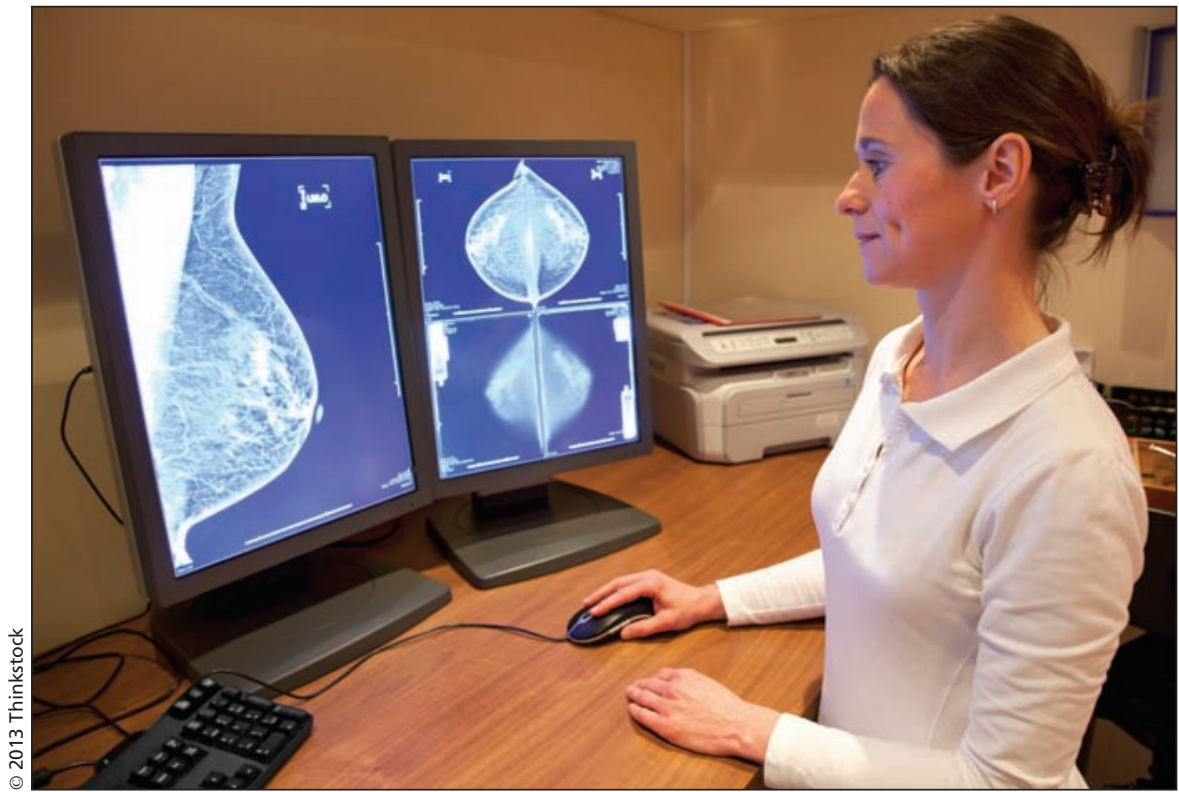

Digital direct mammography offers several advantages over film-based technologies, including the ability to email images directly and enhance them to bring out details.

and may lobby for cheaper technology options. "Physicians should not own diagnostic technology," he says. "It's a fundamental conflict of interest."

Quebec's decision to continue with CR mammography is, however, supported by the official positions of Health Canada and the Canadian Association of Radiologists (CAR). "We don't just look at one study," says Health Canada spokesperson Sean Upton.

"There are other studies that do not show a lower cancer detection rate for $\mathrm{CR}$ and we understand that all studies have strengths and limitations," Dr. Jacques Lévesque, president of the CAR, writes in an email.

The Ontario study, published online in Radiology, found that $\mathrm{CR}$ to have a $21 \%$ lower cancer-detection rate than DR and screen-film mammography (SFM) (http://radiology.rsna.org/content/early /2013/04/29/radiol.13122567.abstract). It is the largest study to date comparing all three mammography screening methods.

The results contradict the only two previous studies, one that concluded CR had a higher rate of detection than film screen (Acta Radiology 2010;51:491-7) and another that found no difference between CR, DR and film screen (Eur J Radiol 2007;64:419-25). However, both studies had significantly smaller sample sizes than the Ontario study, which followed more than 800000 patients, and unlike the Ontario study, neither used concurrent cohorts.

Regarding potential weaknesses of the Ontario study, although the authors did stratify patients according to age, number of previous screenings and breast density, they also point out some of the study's stratified analyses have a potential for "false positive associations." Furthermore, they explain, "results may be limited by inherent differences among women screened with DR, CR or SFM."'

The Ontario study also didn't account for differences in the experience levels of the radiologists, but did cluster radiologists to adjust for this. Moreover, Dr. Derek Muradali, coauthor of the study and radiologist-in-chief of Cancer Care Ontario's Ontario Breast Screening Program, pointed out that his program analyzes each radiologist's performance 
regarding cancer detection, false negatives and false positives. "If someone is an outlier, I call them up and I work with them to make sure they improve," he says. "The quality of radiologists is consistent throughout the program."

Regarding the false positive rates generated by the machines themselves, Dr. Anna Chiarelli, the study's main author, says this is unknown but "would not substantially impact the overall finding of the study."

Interestingly, proponents of DR technology say that both film screen and CR should be discontinued, even though Ontario's study didn't find traditional film screen to be less effective than DR in patients 50-74 years old in the Ontario Breast Screening Program.

"I wish the [Ontario Ministry of Health] would have gone further," says Dr. Mark Prieditis, president of the Ontario Association of Radiologists (OAR). He says his organization presented a report in 2010 to the Ontario Medical Association and the Ministry of Health calling on the province to move all mammographies to full-field digital, which is now the standard in most developed countries, but "it was ignored."
"You can send [digital mammography images] from A to B; you can enhance them after the fact to bring in details," he says.

Given that CR is essentially a scan of a film image, Meterissian and Keyserlingk both see it as an obsolete technology, and argue that digital offers a much sharper image. "If I told people in the US that we are using film screen, they would laugh at us," says Meterissian. - Wendy Glauser, Toronto, Ont.

CMAJ 2013. DOI:10.1503/cmaj.109-4510 